\title{
Eponymous Units in the English Sublanguage of Sport: Form, Meaning and Functioning
}

\author{
Natalia N. Bobyreva ${ }^{1}$ \\ ${ }^{1}$ Kazan (Volga region) Federal University, 420008, Kazan, Russia \\ Correspondence: Natalia N. Bobyreva, Kazan (Volga region) Federal University, Kremlyovskaya Street, 18, \\ Kazan 420008, Russia. E-mail: Nathalienb@yandex.ru
}

\author{
Received: April 14, 2015 Accepted: April 20, 2015 Online Published: April 27, 2015 \\ doi:10.5539/jsd.v8n4p309 URL: http://dx.doi.org/10.5539/jsd.v8n4p309
}

\begin{abstract}
The importance of studying the problem is determined by the fact that the sublanguage of sport is constantly developing, and in this process the definite role belongs to proper names, which is one of the ways of metonymic term formation. The author of the article is aimed at considering the eponymous units in the English sublanguage of sport in the formal, semantic, and functional aspects. The leading method used in the investigation of the material is descriptive analysis alongside studying print and electronic sport dictionaries and glossaries, institutional discourse corpus and interviews with people involved in sport. The terms under study mainly consist of two components, but may be reduced to a proper name. Proper names may function as separate one-word terms as well as be combined within one language unit with words of general vocabulary both in specialized and metaphorical meaning. The eponymous layer in the language of sport is not homogeneous, and includes simple and compound terms, widely and rarely used units, as well as archaisms and neologisms. These terminological units are brief and stylistically neutral. They are highly professional, as their meaning is known mostly by specialists, though they are rather frequently used in popular literature on sports and in mass media. The illustrating fragments of different genres of sport discourse are presented. Linguistic research of sport eponymous terms is of interest for terminological studies from the point of view of terminological systems development, function of proper names in terminology, models of word and phrase formation and translation of professional discourse.
\end{abstract}

Keywords: eponym, proper name, term, terminology, sport terminology, language for specific purposes (LSP), sublanguage of sport, special discourse

\section{Introduction}

Nowadays the investigation of the special sublanguage of sport is highly important due to the following extralinguistic factors: increasing of interest of the world community in sport and its consequent popularization; the demand for translation of texts belonging to different genres of sport discourse as essential means of information exchange. The special language under study demonstrates various means of word and phrase formation. One of them is the use of eponymic forms, which are unique elements in the systems of such professional sublanguages as those of medicine, mathematics, physics, chemistry, geology, culture, etc.

Proper names in special languages carry cultural information and belong to cognitive categories as they maintain information about subjects, phenomena and processes peculiar to particular domains. The research is carried out within the cognitive and anthropocentric approaches. The principle of system underlies the cognitive approach which presupposes studying the external factors of the environment where the sublanguage and its units are used; anthropocentrism focused on human mind, culture, knowledge, etc. dominates in the cognitive linguistics (Vorushilova, 2012). Proper names are base for eponymous terms and their task within the language for specific purposes (LSP) is to name special notions correctly (Novinskaya, 2009).

Another essential point concerning multi aspect study of the eponymous units of sport sublanguage is highlighting the principles of representing them in monolingual and bilingual dictionaries. The problem of dictionaries compellation is of high importance in the modern linguistic paradigm due to its evident applied character and practical demand in the processes of communication and translation (Solnyshkina \& Gafiyatova, 2014). 
English for specific purposes has become a subject of learning for intending interpreters and translators as well as for students studying at non-linguistic faculties and learning the sublanguage of the corresponding sphere for their future careers. In this process of education much attention should be paid to gaining knowledge of the structural elements of the LSP and developing skills of their usage in different situations of professional communication (Ukhanova, 2014). Besides methodology of teaching foreign languages, study of languages for specific purposes involves data of such linguistic fields as lexicology, terminology, translation and discourse analysis (Lanuages for Specific Purposes, 2007).

\section{Methodological Framework}

\subsection{Literature Review}

Language for specific purposes (LSP) is defined as a functional kind of the natural language which accumulates and preserves knowledge of a particular field and serves adequate and efficient communication in the professional sphere (Khomutova, 2008). In modern literature on linguistics much attention is paid to the problem of languages for specific purposes of different spheres. Researchers focus on the problem of term derivation, terminological synonymy, polysemy, status of different units of professional languages, and representing these units by means of lexicography.

Linguists have focused attention on different aspects of eponyms of various fields in different languages. E.M. Kakzanova considered eponymous terms as typical elements of mathematical and medical discourses in German. According to the author, a proper name forming an eponymous term gives it an opportunity to carry information about the culture and history which are interconnected in the perspective of the research (Kakzanova, 2011). The article by Yu.E. Kalugina covers the structural and semantic peculiarities of the English terminology of economics with special regard to the aspects of term formation and distinctive features in semantics (Kalugina, 2010). The structural and semantic features of the English eponym terminology of physics are considered in the paper by Yu.Ye. Kosterina, where the author suggests a solution on the status of eponymous units in the language of science and refers the eponym units to a class of terms in contrast to a class of nomenclature names (Kosterina, 2014). O.V. Kosonogova and M.V. Malashchenko described proper names as productive elements of word-formation in Legal English paying special attention to the modern tendencies of determinalization and interminalization typical of LSP (Kosonogova \& Malashecko, 2014).

Study of eponymous terms has evident practical value. The research by C.L. Beeching was realized in A Dictionary of Eponyms presenting a variety of eponyms in different fields of human development and comprises relevant facts concerning outstanding people whose names became the source for derivation of terms (Beeching, 1989). The Elsevier's Dictionary of Eponyms contains nearly 3000 terms formed on the base of proper names and covers various fields of human activity such as economy, science, technology, culture, sports and some others (Elsevier's dictionary of eponyms, 2001). Each entry provides the term definition which reflects its etymology and an illustrative sentence giving information about how the term is functioning in context.

\subsection{Objectives of the Research}

The objective of the article is to identify the formal, semantic and functional features of eponymous units in the English sublanguage of sport. The article also aims at formulating basic principles of representing eponymous units in a specialised dictionary.

\subsection{Factual Material of the Research}

The article presents the results of the research persuaded on the material of approximately 500 eponymous units denoting sport concepts and formed by means of proper names in the English sublanguage of sport alongside fragments of special discourse illustrating their usage. The author has studied the results of previously published papers on sport terminology and eponymous units in different sublanguages as well as monolingual and bilingual dictionaries of sport vocabulary and eponymous terms. In order to observe the usage of the terms a corpus of texts belonging to different genres of sport discourse was analyzed, and several people involved in sport and physical education were interviewed.

The sublanguage of sports is a system of names for actions, artifacts, sport events, historical precedents and people involved. The eponymous term is understood as a terminological unit having a proper name as an element of its structure. Terms containing proper names are special units within the sublanguage of sport that have unique etymology, formal, semantic and functional characteristics. The etymology of every unit is studied with reference to encyclopaedic resources, books on history of sports, and manuals. 


\subsection{Methods of the Research}

In the process of research the following methods are used:

- descriptive method includes identification, observation and classification of the language items under study;

- method of data sampling involves analyzing monolingual and bilingual dictionaries of sport terms and eponyms and creation of corpus of texts of sport discourse to search for eponyms;

- contextual analysis aimed at finding the peculiarities of eponymous units functioning in terms of stylistic and temporal aspects.

- comparative method, aimed at identifying the international character of the investigated material and finding specific features of a range of examples in the English variant of the sublanguage of sport.

\section{Results}

\subsection{Semantic Aspects of Sport Eponyms in English}

As well as any other lexical layer of language, sport terminology keeps developing, as new referents appear in physical training and sport, new elements and routines are created, new rules of competitions are worked out. New terminological units are formed on the base of native lexical means, as well as with the help of borrowed elements. In this process of terminology development the definite role belongs to proper names, which is one of the ways of metonymic formation of terms. Eponymous units are used with different frequency in figure skating, artistic and rhythmic gymnastics, athletics, boxing, chess and draughts, football, hockey, golf and other kinds of sport. Traditionally, terminology of artistic gymnastics is abundant in eponymous terms. For example, Kovacs salto; Tsukahara vault; Yamashita vault. Eponymous terms of figure skating are frequently used during sport competitions and in press. For instance: Miyahara's program to "Miss Saigon" featured six clean triples including two double Axel-triple toe combinations, but she almost fell on a triple Lutz (ISU World Figure Skating Championships 2015 - Ladies Free Skating). The names of cups awarded in the National Hockey League also derive from proper names: Hart Memorial Trophy, Art Ross Trophy, Calder Memorial Trophy, James Norris Memorial Trophy, Vezina Trophy, Lady Byng Memorial Trophy, Frank J. Selke Trophy, William M. Jennings Trophy, Jack Adams Award, Lester B. Pearson Award, etc. Each subsystem of sport terminology demonstrates different quantitative and qualitative characteristics of its eponymous elements. It can be explained by various extralinguistic factors influencing the history of sport and its terminology, world and national traditions and specific features of different kinds of sport.

The research showed that the eponymous language items in sport sublanguage may be classified into several thematic groups. The first group contains units denoting elements, styles, techniques, methods of performing actions named after athletes. It is well accepted in figure skating and gymnastics when a difficult and original element or combination is named after its first performer at official international competitions (Terminologiya sporta, 2001). For example: Thomas salto is named after American gymnast Kurt Thomas; Azarian cross (after famous Soviet gymnast Albert Azarian); Axel jump (after Norwegian figure skater Axel Paulsen); Vardon Grip (after outstanding golfer Harry Vardon); Salchow jump is invented by Swedish skater Ulrich Salchow. The second group covers names of intellectual actions in chess and draughts. For example: Evans Gambit, Benoni Defense, Alekhine's Defence, Albin Countergambit. The following group of eponymous terms contains the names of sport equipment and apparatuses. For example: Smith machine in bodybuilding, Zdarsky tent in mountaineering. Names of rackets for table tennis are also interesting examples of this category, but they are considered as nomenclature names rather than terms: Timo Boll ALK, Timo Boll ZLF OFF, Timo Boll 5000 are named after German sportsman Timo Boll; Schlager Carbon, Schlager Precision - in honour of Austrian table tennis player Werner Schlager. The fouth group contains names of sports events. For example: Stanley Cup, Allan Cup in hockey; Davis Cup in tennis; Thomas Cup, Uber Cup in badminton; derby in equestrianism. This group comprises an interesting example in which there is no direct connection of the eponym and referent. That is Roland Garros or French Open (French: Les internationaux de France de Tennis or Tournoi de Roland-Garros). It takes place at the Roland Garros Stadium in France named after French aviator Roland Garros who never touched a tennis racket and considered tennis to be a game of poor intellect (Zvezdy mirovogo sporta, 2000). The fifth group of the studied units includes names of sports realia, such as facts, rules or precedents that took place in the history of sports. For example, Bosman ruling in football; Jordan rules in basketball; Marquess of Queensberry in boxing. Names of prizes comprise the sixth group: Val Barker Trophy, Lonsdale Belt in boxing; Conn Smythe Trophy in hockey. The seventh group of eponyms contains names of places where sport events take place: Stadio Giuseppe Meazza, Stadio Mario Rigamonti.

Sport professional communication also employs eponymous terms of other professional spheres. It proves the 
fact that sport terminology is an open developing system, and units of other terminologies penetrate into it. For instance, the following medical terms are used in diving: Valsalva manœvre; Doppler bubble detector (Orlov, 1997). The physical term Magnus effect denotes a phenomenon important in many ball sports.

The obvious advantage of eponyms in sport is the fact that they are not ambiguous, have one meaning and do not depend on the context. However, there are athletes in the history of sport who have given their names to two or more elements: Komova 1. Clear pike circle bwd through hstd with flight and 1/2 turn (180 ) to hang on $H B ; 2$. Clear pike circle bwd through hstd with flight to hang on HB; Kochetkova 1 . Flic-flac with min. $3 / 4$ twist $\left(270^{\circ}\right)$ before hand support; 2. Flic-flac from side position with $1 / 2$ twist $\left(180^{\circ}\right)$ to side hstd lower to optional end position.

Lack in motivation of meaning is one of obvious drawbacks of sport eponyms as speakers of English who are not involved in sport and do not possess special knowledge cannot associate the language form with a referent, as a proper name used as a term does not give any information about its meaning or etymology.

\subsection{Structural Aspects of Sport Eponyms in English}

A typical eponymous term consists of a noun, denoting an action and a proper name. In English a proper name is in pre-position due to the fact that this language belongs to the group of analytical languages. The core element of a compound eponymous special language item is usually a word of language for general purposes either in specialised or metaphorical meaning. The terms under study mainly consist of two elements, but may be reduced to a proper name only. This is mostly typical of the figure skating terminology, in which such word groups as Axel jump and Biellmann spin are reduced to Axel and Biellmann respectively; terms tend to be one-word: Salchow, Lutz. The eponymous terms of figure skating may serve as core components of two-word terms: double Axel; triple Axel; double Salchow; triple Salchow; double Lutz; triple Lutz.

Full forms of artistic gymnastics terms also contain two elements: Radochla roll. The main word of a word-group may be expressed by a metaphor: Maguar spindle; Mukhina flip, Healy twirl. In Code of Points for artistic gymnastics elements are called with surnames of gymnasts and, consequently, consist of one component: Amanar (named after Simona Amanar) Round-off flic-flac on - stretched salto backward with 21/2 turn (900 $)$ off; Moors (named after Victoria Moors) From HB - underswing with salto fwd stretched with $1 / 2$ turn (180 ); Zamolodchikova (named after Elena Zamolodchikova) Round-off in front of beam - flic-flac with $1 / 1$ twist $\left(360^{\circ}\right)$ to hip circle bwd (Code of Points 2013-2016). A name of the mountaineering equipment jumar derived from the first syllables of surnames of Swiss mountaineers Adolph Jusi and Walter Marti.

Due to the need for detalisation and precision eponymous one- or two-word terms have a tendency to add additional components to describe more complex physical exercises forming complex multiword terms: Tsukahara tucked with $1 / 1$ turn $\left(360^{\circ}\right)$ off; Stalder bwd with $1 / 1$ turn $\left(360^{\circ}\right)$ to hstd; Gainer flic-flac with min. $3 / 4$ twist $\left(270^{\circ}\right)$ before hand support. These terms do not meet the requirement for terminological brevity and resemble descriptions or definitions, but continue to be one of characteristic features of sport terminology, as combinations of physical exercises and movements are various.

\subsection{Functional Aspects of Sport Eponyms in English}

Eponymous terms demonstrate their universal character by functioning in texts of different genres of sport discourse. The following example is taken from an online article which is an example of news media language: Hanyu's performance to "The Phantom of the Opera" included eight triple jumps including two triple Axels, but he doubled the planned quad Salchow and missed the quad toeloop (ISU World Figure Skating Championships 2015 - Men Free Skating). The next example is borrowed from the site for bodybuilders providing its readers with necessary information about exercises and tips for their execution: The Arnold press is an invention of the great Arnold Schwarzenegger. This exercise targets both, the front and side deltoids (Building Muscle 101). The Code of Points which belongs to the style of official documents also uses eponymous units: A hand placement mat may be used for Yurchenko vaults only (Code of Points 2013-2016). Consequently, we see that eponymous items may function as elements of various styles of professional discourse in sport and are stylistically neural and devoid of connotations. We should mention that the language units under study are used mainly by the representatives of sport society and rarely function outside this domain.

It is necessary to point out that some eponymous terms denote concepts which are not modern and have become part of history. It is quite natural of language to enrich its vocabulary by adding new words and word groups, but sometimes language items are lost. For example, the swimming style trudgen (named after John Arthur Trudgen) is one of the stages in the development of freestyle swimming. Korbut flip is forbidden by the Code of Points at the official competitions in artistic gymnastics. However, these terminological units are used in special literature 
of encyclopaedic and reference types, dedicated to the history of the development of different kinds of sport. For example: The trudgen is a swimming stroke sometimes known as the racing stroke, or the East Indian stroke (Wikipedia: Trudgen). The form and meaning of such eponyms do not cause any difficulty if they occur in a relevant context, as very often they are accompanied by explanations.

The nomination processes of sports phenomena in different languages have very much in common, as traditionally units of sport terminology denote the referents which are equally defined for different nations. This tendency is explained by the globalization of sport society, common international rules, regulations, standards and requirements for athletes, coaches and judges. For example, the name of style used in the athletics event of high jump Fosbury Flop deriving from the surname of American athlete Richard Douglas Fosbury proves to be an international term as well as the majority of eponymous terms: le Fosbury-flop in French, lo stile Fosbury in Italian, фосбери-флоп in Russian. However, terms have a tendency to have national characteristics, both formal (in word and phrase formation) and semantic. The loan translation of this term was done into many languages and it has been being used for half a century in professional discourse. However, there are some instances of asymmetry between different languages. For example, the jump denoted by the two-word metaphorical term loop jump is credited to German figure skater Werner Rittberger and has an equivalent Rittberger in German and Italian languages and риттбергер in Russian.

\subsection{Basic Principles of Lexicographic Representation of Eponymous Units}

The investigation of units of languages for specific purposes containing proper names has a practical value. The existing monolingual and bilingual glossaries and dictionaries do not contain a full range of eponyms used in sport. Therefore, a compilation of a dictionary specialized in sport eponyms is of importance for modern lexicography. The structure of the dictionary entry should depend on the type of the dictionary and the target user.

In our opinion, lexicographic representation of eponyms should contain some information of the encyclopaedic kind reflecting the etymology of the unit. A dictionary of every type performs the function of a reference book aimed at knowledge acquisition by its users. The dictionary entry may be complicated as some athletes have given their names to several concepts and the problem of representing polysemic eponyms is to be solved. Eponymous terms with other elements of the sublanguage may be shown in word groups (multiword terms) containing eponym in the structure. Example sentences should be presented for illustrating how the describe units are used in special contexts. Fragments of special discourse are supposed to be chosen from texts of different genres of sport discourse in print and online: articles about athletes and results of sport events, encyclopaedias about the history of sports and games, manuals, reference books, scientific papers on training athletes and introduction of scientific findings into the practical activity. We support the principle of authenticity in choosing the illustrating sentences: they should not be shortened or adapted in order to give a reader better understanding of the role of a particular eponymous unit in special discourse.

Use of a proper name as an element of LSP in the intercultural communication involves problems of spelling and pronunciation. In a bilingual dictionary of eponyms it is advisable to place transcription. It is recommended to give the example sentences in both source and target languages. Moreover, transliteration may cause variants of spelling in a language with another writing system. For example, the term Forsbury has two variants in Russian: фосб̄ери (more widespread) and фосбюри.

\section{Discussions}

Eponyms of sport have not been exposed to many-sided detailed study, though were touched upon in works of some investigators. For example, in the paper by E.I. Gureeva it is highlighted that eponyms are a special kind of language units in the system of modern sport terminology alongside genuine terms, nomenclature names, and terms used by judges to control the competition; professional jargon and slang items are units of non-codified vocabulary (Gureeva, 2011). The thesis by V.E. Briginevich is aimed at a complex research of the terminological system of mountaineering in English, and the eponymous units, though inconsiderable in number, are thoroughly considered (Briginevich, 2014). The lexical status of eponymous units of specific language of sport is deeply studied in the research by Elistratov A.A., and non-codified units of the Russian sublanguage of sport are described in details in terms of etymology, structure and functioning (Elistratov, 2009).

\section{Conclusion}

The semantic analysis has showed that eponymous units form a subsystem in a larger complicated system of the sublanguage of sport. They have precise meaning; the bulk of the units under study possess only one meaning. The research showed that the eponymous language items in sport may denote elements, styles, techniques, 
methods of executing movements, intellectual actions sport equipment and apparatuses, names of sports events and prizes, sports realia, such as facts, rules or precedents that took place in the history of sports, and places of sport events.

The structural classification of eponymous units used in sports demonstrates various models which differ in accordance with different traditions in naming movements, competitions, equipment, etc. in different kinds of sport. Eponymous language item may be simple (consisting of one word) and may be a component of two-word or multiword terms. In complex eponymous units proper names may function as modifying or main elements. Brevity, derivation capacity and formal variation are formal characteristics of eponyms used in sport.

The international character (equivalence of semantics in different languages), and usage in different styles and genres of sports discourse are functional characteristics of eponymous terms. They are highly professional, as their meaning is known mostly by specialists, though they are sometimes used in mass media. The terms under study are mainly used in professional literature of encyclopaedic and reference types, dedicated to the history of the development of different kinds of sport, as well as in official documents on sport and textbooks.

Thus, the layer of eponymous units in sports is not homogeneous, and includes simple and compound items, widely and rarely used units, neologisms and units denoting subjects which are not used or elements which are not performed nowadays.

\section{Recommendations}

Linguistic research of sport eponymous terms of all categories, including archaisms and neologisms, are interesting for terminological studies from the point of view of special languages development, role of proper names in languages for specific purposes, models of word and phrase formation and translation of professional discourse texts.

The findings may be of interest for linguists who investigate languages for specific purposes (in particular, the sublanguage of sport), theory of proper names, and sociolinguistics. While carrying out the research, the author has accumulated a certain amount of factual material which may be published as a lexicographic resource meant for linguists, translators, interpreters, athletes and those who are interested in sport terminology. The results of the study may be used for comparative analysis of sport terms in different languages and find their application in bilingual or multilingual dictionaries.

\section{Acknowledgments}

The work is performed according to the Russian Government Program of Competitive Growth of Kazan Federal University

\section{References}

Beeching, C. L. (1989). A dictionary of eponyms (3rd ed.). The Library Association. London.

Briginevich, V. E. (2014). English Terminology of Mountaineering: structural, cognitive and discourse approaches (Doctoral dissertation). Pyatigorsk. Pyatigorsk State Linguistic University.

Building Muscle 101. From the Beginner to the Advanced Weight Lifter. (2013). Retrieved April 4, 2015, from http://www.building-muscle101.com/arnold-press.html

Code of points 2013-2016: Women's Artistic Gymnastics. (2014, December 17). Retrieved April 4, 2015, from http://www.fig-gymnastics.com/publicdir/rules/files/wag/WAG\%20CoP\%202013-2016\%20(English)\%20N ov\%202014.pdf

Elistratov, A. A. (2009). Non-terminological vocabulary of sport containing proper names. Bulletin of Chelyabinsk State University. 34(172). Philology. Study of Arts. Issue, 36, 26-32.

Elsevier's dictionary of eponyms. (2001). Comp. by Rogelio A. \& Letusé La O. La Havana, Cuba. (1st ed.). Elsevir.

Gureeva, E. I. (2011). Kinds of special units in modern sport terminology. Bulletin of Chelyabinsk State University, 24(239). Philology. Study of Arts. Issue, 57, 71-73.

ISU World Figure Skating Championships 2015 - Ladies Free Skating. (2015, March 28). Retrieved April 4, 2015 , http://www.isu.org/en/single-and-pair-skating-and-ice-dance/news/2015/03/isu-world-fs-champs-2015-ladie $\mathrm{s}-\mathrm{fs}$.

ISU World Figure Skating Championships 2015 - Men Free Skating. (2015, March 28). Retrieved April 4, 2015, 
from

http://www.isu.org/en/single-and-pair-skating-and-ice-dance/news/2015/03/isu-world-fs-champs-2015-menfs

Kakzanova, E. M. (2011). Linguo-cognitive and cultural peculiarities of scientific discourse: by the material of mathematic and medical eponymous terms (Doctoral dissertation). Moscow. Institute of Linguistics of Russian Academy of Sciences.

Kalugina, Yu. E. (2010). Structural and semantic characteristics of eponyms in the sublanguage of economics. Bulletin of MSRU. Series Linguistics (Vestnik Moskovskogo gosudarstvennogo oblastnogo universiteta. Seriâ Lingvistika), 3, 74-79.

Khomutova, T. N. (2008). Language for Specific Purposes (LSP): the linguistic aspect. IZVESTIA: Herzen University Journal of Humanities and Sciences, 71, 96-106.

Kosonogova, O. V., \& Malashchenko, M. V. (2014). Word-formation models of proper name-based terms in Legal English. Bulletin of Kemerovo State University, 3-1(59), 174-180.

Kosterina, Yu. Ye. (2014). Eponym units in English terminology of physics. Bulletin of Irkutsk State Linguistic University, 2, 76-82.

Languages for Specific Purposes: Searching for Common Solutions. (2007). edited by Dita Gálová. Cambridge Scholars Publishing.

Novinskaya, N. V. (2009). Semantics of a proper name in the structure of the term: historical aspect. Vestnik of Astrakhan State Technical University, 1, 137-139.

Orlov, D. V. (1997). English-Russian, Russian English Diving Dictionary for Scuba-Divers. Moscow. EDDA.

Solnyshkina, M., \& Gafiyatova, E. (2014). Modern forestry English: macro- and microstructure of low register dictionary. Journal of Language and Literature, 5(4), 220-224.

Terminologiya sporta. Tolkovy slovar sportivnykh terminov. (2001). [Terminology of Sport. Monolingual dictionary of sport terms]. Comp. by F.P.Suslov, D.A.Tyshler. Moscow. SportAkademPress.

Trudgen. (2014, July 6). In Wikipedia, the free encyclopedia. Retrieved April 4, 2015, from http://en.wikipedia.org/wiki/Trudgen

Ukhanova, E. V. (2014). English for Specific Purposes. Historical Aspect. Philological Sciences. Issues of Theory and Practice, 4(34), 1, 206-209.

Vorushilova, S. A. (2012). Study of prototerminological level in development of terminology on the basis of cognitive and anthropocentric approaches. Bulletin of MSRU. Series Linguistics (Vestnik Moskovskogo gosudarstvennogo oblastnogo universiteta. Seriâ Lingvistika), 2, 4-14.

Zvezdy mirovogo sporta. (2000). [Stars of the world sport]. Comp. by V.N.Pustovoytov. Rostov n/D: Fenix.

\section{Copyrights}

Copyright for this article is retained by the author(s), with first publication rights granted to the journal.

This is an open-access article distributed under the terms and conditions of the Creative Commons Attribution license (http://creativecommons.org/licenses/by/3.0/). 